\title{
Analyzing Responses, Moves, and Roles in Online Discussions
}

\section{Craig Wishart \\ Fayetteville State University, Fayetteville, NC, USA}

\author{
Retta Guy \\ Tennessee State University \\ Nashville, TN, USA
}

rguy@tnstate.edu

\begin{abstract}
There is much debate regarding the value and utility of grading discussions to ensure and assess full participation in the online classroom. Proponents of threaded discussions view it as an integral part of the learning process, where students seek knowledge and express understanding. Consequently, they deem it essential to assess participation. On the other hand, opponents of assessing or grading participation assert that an exceedingly active discussion can distract students from other equally or more important coursework, not to mention the impracticality of instructors responding to the vast number of submissions.

This article examines a variety of grading rubrics used to promote critical thinking about course content and assess the quality of participation and contributions of online threaded discussions. We present the results of a study conducted at a historically Black institution that used Kneser's Exchange Structure Analysis (ESA) to analyze dialogue in order to understand student exchanges, moves, and roles as well as the influence of gender in online discussions during 3 consecutive summer sessions.
\end{abstract}

Keywords: asynchronous, communication technologies, discourse, e-learning, exchange structure analysis, grading rubrics, online discussions.

\section{Introduction}

The advancement of the World Wide Web and virtual learning environments has profoundly impacted asynchronous communication technologies, featuring tools that facilitate meaningful discourse between and among learners and educators. As defined by Duffy and Cunningham (1996), meaningful discourse is a process of constructing knowledge and exchanging ideas and different viewpoints. Constructivist learning supports meaningful discourse by enabling students to construct knowledge through reflection, prior knowledge and experiences, (Jonnassen, Davidson, Collins, Campbell, \& Bannan-Haag, 1995).

Material published as part of this publication, either on-line or in print, is copyrighted by the Informing Science Institute. Permission to make digital or paper copy of part or all of these works for personal or classroom use is granted without fee provided that the copies are not made or distributed for profit or commercial advantage AND that copies 1) bear this notice in full and 2) give the full citation on the first page. It is permissible to abstract these works so long as credit is given. To copy in all other cases or to republish or to post on a server or to redistribute to lists requires specific permission and payment of a fee. Contact Publisher@,InformingScience.org to request redistribution permission.
The online environment has provided more opportunities for learners to participate in collaborative technologies such as e-mail, discussions, chat rooms, whiteboards, and announcements. These asynchronous communication tools have enhanced learning in the online environment across the globe, as well as augmented classroom online discussions by supporting reflection, 
social negotiation and knowledge construction (Gilbert \& Dabbagh, 2005).

One of the most common means of asynchronous communication is the "threaded" discussion that Hewitt (2005, p. 568) defines as "a hierarchically organized collection of notes in which all notes but one (the note that started the thread) is written as 'replies' to earlier notes." Because of its hierarchical structure, threading allows students to trace conversational chains of messages that relate to the original subject.

Countless course designers and educators recognize the value of online discussions but keeping the discussion threads lively and informative is a challenge. Consequently, there is an ongoing debate about the value and utility of grading discussions to ensure and assess full participation in the online classroom.

Proponents of threaded discussions view it as an integral part of the learning process, where students seek knowledge and demonstrate understanding. Consequently, they deem it essential to assess participation. Salmon (2005) contends that online discussion promotes active thinking and interaction with others. Levenburg and Major (2000) suggest that assessing participation (a) recognizes students' workload and time commitment with respect to online discussions and (b) encourages students to participate in required learning activities associated with the discussions. Finally, a number of researchers agree that assessment criteria can be used as a guide to students for learning outcomes and expected quality of thinking (Celentin, 2007; Ho, 2002; Kneser, Pilkington, \& Treasure-Jones, 2001; McKenzie \& Murphy, 2000).

On the other hand, Davis (1993) and Lacoss and Chylack (1998) feel that grading or assessing online discussions is counterproductive to facilitating positive learning outcomes. Without compelling empirical evidence to support his claim, Davis (1993) also suggests that assigning grades to participation may discourage free and open discussion and that the process disadvantages introverted or shy students. Opponents of assessing or grading participation assert that an exceedingly active discussion can distract students from other equally or more important coursework, not to mention the impracticality of instructors responding to the vast number of submissions.

The current article examines a variety of grading rubrics used to promote critical thinking about course content and assess the quality of participation and contributions of online threaded discussions. We present the results of a study conducted at a historically Black institution that used the Exchange Structure Analysis (ESA) developed by Kneser et al. (2001) to analyze dialogue and student roles in online discussions during 3 consecutive summer sessions. The following questions were postulated for this study:

(1) What were students preferred 'initiate and respond exchanges' in the online discussions?

(2) What were students preferred 'moves' in the online discussions?

(3) What were students preferred 'roles in the online discussions?

(4) Were there different patterns of participation based on gender?

\section{Grading Rubrics for Online Discussions}

Lively online discussions can be facilitated by requiring participants to not only post their own work, but also comment and respond to each others submissions. As a result, the discussions become more than just an assignment; students learn from each other and become more engaged in the learning process. Unfortunately without requirements for participation, students often elect not to engage in the dialogue for various reasons of time management, passivity, interest, disregard, etc. Additionally, when the requirement for participation in the discussions only counts for a small percentage of the grade (e.g., 5\%) participation may still be less than satisfactory, as students assess the rate of return for time and effort. 
Brannon and Essex (2001) make the following recommendations for instructors in order to reach full and appropriate participation.

Instructors must provide students with clear communication protocols and clear requirements for posting and reading discussion entries to guard against potential pitfalls of asynchronous communication such as "feelings of social disconnection" that could result from (a) lack of immediate feedback, (b) lack of daily participation in discussions, and (c) lack of time necessary for students to develop thoughtful discussions. (p. 36)

Rubrics can be used as an instructional guide to communicate expectations to students and as an assessment to evaluate student participation. Chang (2008) developed a five-point grading scale to examine the quality of online discussions. The evaluation form focused on four aspects: depth, appropriateness, correctness, completeness, and usefulness, each consisting of three issues respectively as outlined in Table 1 .

Table 1: The Evaluation Form for Online Discussions (source: Chang, 2008)

\begin{tabular}{|l|l|l|}
\hline \multicolumn{1}{|c|}{ Types of Online Discussions } & \multicolumn{1}{|c|}{ Aspects of Evaluation } & \multicolumn{1}{c|}{ Issues } \\
\hline Public Discussions & Depth & $\begin{array}{l}\text { Meaningfulness } \\
\text { Insight } \\
\text { Knowledge level }\end{array}$ \\
\hline $\begin{array}{l}\text { Project-Based Group Discus- } \\
\text { sions }\end{array}$ & Appropriateness & $\begin{array}{l}\text { Relevance } \\
\text { Clarity of diction } \\
\text { Logic correction of writing }\end{array}$ \\
\hline $\begin{array}{l}\text { Jigsaw Expert Group Discus- } \\
\text { sions }\end{array}$ & Completeness & $\begin{array}{l}\text { Richness } \\
\text { Creativity } \\
\text { Criticism }\end{array}$ \\
\hline & Usefulness & $\begin{array}{l}\text { Feedback to peer } \\
\text { Contribution to community } \\
\text { Helpfulness for solving problems }\end{array}$ \\
\hline
\end{tabular}

In utilizing this evaluation tool, Chang conducted a case study that involved 15 pre-service teachers enrolled in the Instructional Media course at the University of Northern Taiwan. The participants were randomly divided into 5 groups in which they were instructed to select and evaluate teaching websites. This evaluation form was used to collect information regarding discussion content and frequency. The results indicate a positive correlation between online frequencies and Project-Based Group discussions as well as a high degree of participation.

Jeong (2005) supports the use of sequential analysis to determine the affect of latent variables (e.g., message function, response latency, communication style) and exogenous variables (e.g., gender, discourse rules, context) on eliciting responses. He also uses a frequency matrix to analyze and identify patterns in message-response sequences, employing a coding scheme that consists of 4 categories (e.g. argument, challenge, explain, evidence) thereby producing 4x4 matrix. Jeong's initial study using this method examined the effects of specific variables on group interaction in online discussions and discovered that: (1) postings were significantly higher than expected with an overall response rate of $67 \%$ across all categories and (2) message function (latent variable) and gender (exogenous variable) were more likely to elicit a response message. Using the same method of analysis, Jeong and Frazier (2008) examined how messages are posted during the day (early, midweek and weekend) affect the number of responses elicited by the four types 
of exchanges (eg. argument, challenge, explain, evidence). Results found that 'day' of posting significantly affect the number of responses elicited per message.

Palmer, Holt, and Bray (2007) recommend analyses that include both quantitative (number of postings, length of posting, number of messages read, etc.) and qualitative terms (Does the posting exhibit cognitive/social/teaching presence?). They conducted a study using this evaluation technique to investigate the impact of participation in online discussions on student performance. Study results indicate that assessing online discussions positively impacted students' participation and final grades.

Gilbert and Dabbagh (2005) developed a rubric that awarded a point value to excellent, good, average and poor postings. In addition to the following evaluation criteria, students were required to contribute 5-6 postings over the six-day discussion period:

(a) timely discussion contributions,

(b) responsiveness to others' postings,

(c) knowledge and understanding of assigned reading, and

(d) ability to follow the online discussion protocols.

Gilbert and Dabbagh's addition of the online discussion evaluation rubric influenced meaningful discourse and revealed an increase in the number of postings per student when used for assessing asynchronous online discussion forums.

Anderson and Krathwhoh (2001) developed a rubric based on Bloom's Taxonomy (see Table 2). They defined three levels of responses: Low (knowledge and comprehension; Medium (Application and Analysis); and High (Synthesis and Evaluation). A list of process and behavior oriented descriptors are employed to define the levels of thinking requisite the appropriate level.

\begin{tabular}{|l|c|l|}
\hline \multicolumn{3}{|c|}{$\begin{array}{c}\text { Table 2: Rubric for Evaluation of Online Discussion Prompts \& Responses } \\
\text { (source: Anderson \& Krathwohl, 2001) }\end{array}$} \\
\hline \multicolumn{1}{|c|}{ Levels of Thinking } & Points & \multicolumn{1}{c|}{ Process Verbs \& Behavior Descriptors } \\
\hline $\begin{array}{l}\text { Low: } \\
\text { Remember or Understand }\end{array}$ & 1 & $\begin{array}{l}\text { Explain, list, describe, recall, define, identify, } \\
\text { show, restate, summarize, list, demonstrate, illus- } \\
\text { trate, explain }\end{array}$ \\
\hline $\begin{array}{l}\text { Medium: } \\
\text { Apply or Analyze }\end{array}$ & 2 & $\begin{array}{l}\text { Organize, classify, relate, prioritize, discuss, group, } \\
\text { model, apply, compare, contrast, distinguish, cate- } \\
\text { gorize, take apart, combine }\end{array}$ \\
\hline $\begin{array}{l}\text { High: } \\
\text { Evaluate or Create }\end{array}$ & 3 & $\begin{array}{l}\text { Extend, design, reconstruct, reorganize, create, de- } \\
\text { velop, speculate, propose, predict, generate, inter- } \\
\text { pret, judge, justify, critique, evaluate use criteria, } \\
\text { dispute }\end{array}$ \\
\hline
\end{tabular}

Christopher, Thomas, and Rallent-Runnels (2004) utilized the above rubric (see Table 2) to investigate the levels of thinking in an online discussion forum of a graduate course. The results indicated that the majority of responses fell in the medium level, revealing students' ability to analyze and apply knowledge in their responses.

Hewitt (2003) suggests an analysis of student use of threaded discussions based on the characteristics of four thread types:

(1) stand-alone - notes that introduce new ideas to the conference and do not build on previous lines of inquiry. One that begins a new thread. 
(2) Add-on - a note that builds on the ideas of one other note in the conference. One person responds to an idea that someone else has introduced.

(3) Multiple reference - notes that make a reference to two or more previous notes, but not in a way that would be considered an attempt at convergence.

(4) Convergent - a note that discusses some of the ideas expressed in two or more other notes in the conference. (p. 39)

Hewitt's use of this assessment tool suggests that students respond overwhelmingly to the more recent notes in a discussion despite the relevance to the conceptual issues of the earlier notes, revealing that students are more likely to read the latest thread than read earlier threads. Quite the reverse was found in the study conducted by Lisa de Bruyn (2004) when examining students' engagement and dispositions, with $75 \%$ of students posting add-on notes in response to postings of previous students.

Lisa Lobry de Bruyn (2004) used the following rubric (see Table 3) to measure the level of social presence, cognitive and system responses identified in student postings. This two-year study, involving inquiry-based learning activities, revealed that over $50 \%$ of the postings contained some form of social presence.

\section{Table 3: Evaluation of Social Presence (source: de Bruyn, 2004)}

\begin{tabular}{|l|l|}
\hline \multicolumn{1}{|c|}{ Content Analysis } & \multicolumn{1}{c|}{ Definition } \\
\hline Interactive responses & $\begin{array}{l}\text { Includes complimenting, expressing appreciation or agreement, } \\
\text { asking unsolicited questions, referring to others' messages, quot- } \\
\text { ing from others' messages and continuing a thread. }\end{array}$ \\
\hline Affective responses & $\begin{array}{l}\text { Includes expressing emotion, feeling or mood, use of humor and } \\
\text { self-disclosure. }\end{array}$ \\
\hline Cohesive responses & $\begin{array}{l}\text { Includes addressing or referring to other students by name, and/or } \\
\text { group as we, us, our, group, and salutations. }\end{array}$ \\
\hline Cognitive responses & Includes discussion and commentary on the unit content. \\
\hline System responses & Includes discussion related to the software or access issues. \\
\hline
\end{tabular}

The rubrics presented are just a few examples of what designers and instructors have used to articulate clear and explicit guidelines in order to promote participation and quality postings for online discussions. While these studies demonstrate that asynchronous online communication offers the promise of increased student interaction, the influence of gender differences upon the number of participants, the type of participation and/or the dynamics of participation in online threaded discussions was only addressed in the study conducted by Jeong (2005). Interestingly, the literature on this topic is largely inconclusive.

With regard to participation in traditional classroom discussions, the literature documents that male students: (a) interact with instructors more frequently; (b) tend to ask more questions and speak more frequently; and (c) in general dominate the classroom discussion when compared to female students (Canada \& Pringle, 1995; Sadker \& Sadker, 1994)). Some argue that this dominance is a result of discrimination, stereotypes, and sexist views of women (Crombie, Pyke, Silverthorn, Jones, \& Piccinin, 2003; Hall \& Sandler, 1984), consequently, this systematic discrimination disadvantages women in the online environment.

When quantitatively exploring gender differences in online discussions, a predominance of the literature found that men dominated the conversational floor (Barrett \& Lally, 1999; Sierpe, 2001; 
Yates, 2001), while still others found equal participation of women and men (Davidson-Shrivers, Morrison, \& Sriwongkol, 2003; Masters \& Oberprieler, 2004; McLean \& Morrison, 2000; Poole, 2000). On the other hand, a number of studies revealed that women post and read more messages than their male counterparts (Anderson \& Haddad, 2005; Bellman, Tindimubona, \& Arias., 1993; Bostock \& Lizhi, 2005; Gunn, McSporran, Macleod, \& French, 2003; Wolfe, 2000).

The literature also documents the dynamics of online discussions with focus on various communication patterns in determining gender differences. For example, Carr, Cox, Eden, \& Hanslo (2004) examined the exchanges of online communications and found that female students were more likely to focus on community-building moves while male students focused more on adversarial moves, classified as ritualized adversarial exchanges. Furthermore, as analyzed using Kneser's Exchange Structure Analysis, male students exhibited a stronger preference for the 'challenge' and clarify moves while female students preferred the 'feedback', 'inform', 'inquire', 'reason', and 'justify' moves.

This study will contribute to the literature by examining the gender patterns of participation and the initial exchanges, moves and roles of students in online discussions utilizing the Exchange Structure Analysis (Kneser et al., 2001).

\section{Study Background}

The Exchange Structure Analysis (ESA) developed by Kneser et al. (2001) was used in the current study to analyze responses, moves, and roles of students in online discussions. The ESA was chosen because of its widespread use, simple coding techniques, and for current and future comparisons. The reliability of dialogue analysis in category assignment to transcript data was ensured by the following process: (a) employing the use of ESA code structure; (b) checking and verifying qualitative coding; (c) intra-coding reliability between instructor and researchers; and (d) researcher's role as instructor and principal evaluator.

This method of evaluation (ESA) investigates the dynamics of taking turns in online discussions, in which a turn is defined as "a contribution by a particular participant and is delimited by that person starting and stopping speaking" (Kneser et al., 2001, p. 65). The ESA categories are based on Sinclair and Coulthard's (1975) transactional analysis. As explained in Table 4, exchange is defined as "a combination of Initiate and Respond moves, which together make up a classroom dialogue" (p. 65).

\begin{tabular}{|l|l|}
\hline \multicolumn{2}{|c|}{ Table 4: Initiate \& Respond Categories (source: Kneser et al., 2001) } \\
\hline Initiate (I) & $\begin{array}{l}\text { a contribution that anticipates a response and is not predicted } \\
\text { from a previous turn. }\end{array}$ \\
\hline Respond (R) & $\begin{array}{l}\text { a contribution that is not initial, does not anticipate a turn and } \\
\text { usually completes an exchange. }\end{array}$ \\
\hline Reinitiating (RI) & $\begin{array}{l}\text { a contribution that is a continuation of a current exchange and } \\
\text { anticipates a response, but was not predicted from an earlier turn } \\
\text { and was not initial. Feedback can be negative. }\end{array}$ \\
\hline Response-complement (RC) & $\begin{array}{l}\text { a contribution that can be acknowledgement, feedback or evalua- } \\
\text { tion. Response-complement signals intention to close the ex- } \\
\text { change, however, it can be followed by a new change. }\end{array}$ \\
\hline Stand alone (SA) & $\begin{array}{l}\text { contributions in which one participant continues to initiate, and } \\
\text { where turns by the same speaker follow each other. }\end{array}$ \\
\hline Ill-informed turn (II) & a contribution that is an island, with no response to it. \\
\hline
\end{tabular}


ESA includes a set of moves (see Table 5) reflecting statements that challenge, justify, clarify, provide feedback, inform, inquire, or provide reason for current posting.

Table 5: Types of Moves in ESA (source: Pilkington, 1999)

\begin{tabular}{|l|l|}
\hline Challenge & Statements requesting reasoning or fresh thinking \\
\hline Justify & Reply with evidence or contraindication \\
\hline Clarify & Questions of clarification \\
\hline Feedback & Evaluative statements \\
\hline Inform & Description/differentiation \\
\hline Inquire & Questions requesting information \\
\hline Reason & State causal proposition \\
\hline
\end{tabular}

These 'moves' further define a participant's argument role preference (see Table 6). For example, a participant with a preference for statements categorized as the 'reason' move will obtain the role of an 'Explainer; in the same way, a participant with a preference for statements categorized as the 'inform' move will obtain the role of an 'Elaborator' and so forth.

\begin{tabular}{|l|l|l|}
\hline \multicolumn{2}{|c|}{ Table 6: ESA roles (Source: Pilkington, 1999) } \\
\hline Argument role & Anticipated ESA category & Anticipated move category \\
\hline Explainer & Initiate & Reason \\
Elaborator & Initiate & Inform \\
Inquirer & Initiate & Inquire \\
Critic & Reinitiate & Challenge and justify \\
Clarifier & Reinitiate & Clarify \\
Evaluator & Response-complement & Feedback \\
Narrator & Stand alone & Inform and reason \\
Explainer & Respond & Reason \\
Elaborator & Respond & Inform \\
\hline
\end{tabular}

The discussions analyzed in this study came from three online MBA International Business courses offered during the summer from 2004 to 2006 using the Blackboard Learning Management System. These courses were designed in the e-learning format, in which the instructor guided the class with assigned chapter readings, lecture notes, PowerPoint slides, and videos posted with the course management tools as outlined in Table 7 . The quizzes, examinations, and written assignments were also posted and administered on Blackboard. Collaborative learning was created through the discussion board, where students engaged in open dialogue with the instructor and each other about their current event reports and topical questions. The threaded discussions represented class participation, which was evaluated based upon the quality and quantity of each student's postings.

\section{Table 7: Course Requirements \& Grading Criteria}

Year 1 (Summer 2004)

$40 \%$ - 2 Case Analyses

35\% - 8 Current Event Reports

$15 \%$ - 15 Quizzes

10\% - Discussion Board Participation 


\begin{tabular}{|ll|}
\hline Year 2 (Summer 2005) & $30 \%-2$ Case Analyses \\
& $20 \%-5$ Current Event Reports \\
& $25 \%-2$ Short Answer Exams \\
& $20 \%-18$ Quizzes \\
& $5 \%$ - Discussion Board Participation \\
\hline Year 3 (Summer 2006) & $30 \%-2$ Case Analyses \\
& $20 \%-5$ Current Event Reports \\
& $25 \%-2$ Short Answer Exams \\
& $20 \%-18$ Quizzes \\
& $5 \%$ - Discussion Board Participation \\
\hline
\end{tabular}

Other than the multiple choice quizzes, the courses were writing intensive. In addition to discussion board participation, the ten week courses required in-depth case analyses, current event reports, and essay exams. While the criteria for discussion board participation remained consistent across the three years, other requirements for the course changed in years 2 and 3. With the addition of two short answer exams, as well as three quizzes, and the reduction of current event reports from 8 to 5 , the relative weight of all course requirements changed. Specifically, discussion board participation decreased from $10 \%$ to only $5 \%$ of the overall grade summers 2 and 3 . Importantly, because the syllabus neither quantified any specific number of postings required nor included a rubric describing quality, the instructor was responsible for coaching student involvement and ensuring quality postings.

\section{Results}

The analyses were divided into two phases in response to the research questions posited for this study. In phase one, descriptive statistics were used to determine student responses, moves and roles in the online discussions.

Results for the Initiate and Respond category as indicated in Table 8, revealed that in summer 1 , 2 , and 3 the number of postings that were "Initiate" statements progressively increased $(58.2 \%$, $61.2 \%$, and $69.8 \%$, respectively), while the remaining responsive statements to current exchanges declined over the three summers $(39.5 \%, 35.8 \%$, and $30.3 \%)$.

\begin{tabular}{|l|c|c|c|c|c|c|}
\hline \multicolumn{7}{|c|}{ Table 8: Initiate \& Respond } \\
\hline & \multicolumn{2}{|c|}{ Summer 1 } & \multicolumn{2}{c|}{ Summer 2 } & \multicolumn{2}{c|}{ Summer 3 } \\
\hline & Count & Percent & Count & Percent & Count & Percent \\
\hline Initiate & 252 & $58.2 \%$ & 123 & $61.2 \%$ & 67 & $69.8 \%$ \\
\hline Respond & 79 & $18.2 \%$ & 43 & $21.4 \%$ & 9 & $9.4 \%$ \\
\hline Reinitiate & 18 & $4.2 \%$ & 8 & $4.0 \%$ & -- & -- \\
\hline $\begin{array}{l}\text { Response- } \\
\text { complement }\end{array}$ & 74 & $17.1 \%$ & 21 & $10.4 \%$ & 18 & $18.8 \%$ \\
\hline Stand alone & 9 & $2.1 \%$ & 6 & $3.0 \%$ & 2 & $2.1 \%$ \\
\hline Ill-formed turn & 1 & $.2 \%$ & -- & -- & -- & -- \\
\hline
\end{tabular}

All seven types of 'moves' coded in this research are illustrated in Table 9. In all 3 summer sessions, 'inform' move was most active reporting $64.2 \%$ in summer $1,72.6 \%$ in summer 2 , and 
$74 \%$ in summer 3 . The reverse was seen with 'justify and clarify' moves reporting $2.1 \%$ and $.9 \%$ participation in summer $1,1.5 \%$ and $.5 \%$ in summer 2 , and no participation in either category for summer 3 .

\begin{tabular}{|c|c|c|c|c|c|c|}
\hline & \multicolumn{2}{|c|}{ Summer 1} & \multicolumn{2}{|c|}{ Summer 2} & \multicolumn{2}{|c|}{ Summer 3} \\
\hline & Count & Percent & Count & Percent & Count & Percent \\
\hline Challenge & 5 & $1.2 \%$ & 4 & $2.0 \%$ & 1 & $1.0 \%$ \\
\hline Justify & 9 & $2.1 \%$ & 3 & $1.5 \%$ & -- & -- \\
\hline Clarify & 4 & $.9 \%$ & 1 & $.5 \%$ & -- & -- \\
\hline Feedback & 75 & $17.3 \%$ & 22 & $10.9 \%$ & 18 & $18.8 \%$ \\
\hline Inform & 278 & $64.2 \%$ & 146 & $72.6 \%$ & 71 & $74.0 \%$ \\
\hline Inquire & 28 & $6.5 \%$ & 7 & $3.5 \%$ & 3 & $3.1 \%$ \\
\hline Reason & 34 & $7.9 \%$ & 18 & $9.0 \%$ & 3 & $3.1 \%$ \\
\hline
\end{tabular}

The 'elaborator' (initiated by the 'inform' move) was the preferred role for summer $1(49.7 \%)$, summer $2(58.2 \%)$, and summer $3(66.7 \%)$ while the 'clarifier' role was less than dominant with $.9 \%$ in summer $1, .5 \%$ in summer 2 , and $1.0 \%$ in summer 3 . See Table 10 for complete role preferences.

\begin{tabular}{|l|c|c|c|c|c|c|}
\hline & \multicolumn{2}{|c|}{ Summer 1 } & \multicolumn{2}{c|}{ Summer 2 } & \multicolumn{2}{c|}{ Summer 3 } \\
\hline & Count & Percent & Count & Percent & Count & Percent \\
\hline Explainer & 8 & $1.8 \%$ & 1 & .5 & -- & -- \\
\hline Elaborator & 215 & $49.7 \%$ & 117 & $58.2 \%$ & 64 & $66.7 \%$ \\
\hline Inquirer & 28 & $6.5 \%$ & 6 & $3.0 \%$ & 3 & $3.1 \%$ \\
\hline Critic & 14 & $3.2 \%$ & 7 & $3.5 \%$ & 1 & $1.0 \%$ \\
\hline Clarifier & 4 & $.9 \%$ & 1 & $.5 \%$ & -- & - \\
\hline Evaluator & 75 & $17.3 \%$ & 22 & $10.9 \%$ & 18 & $18.8 \%$ \\
\hline Narrator & 9 & $2.1 \%$ & 7 & $3.5 \%$ & 2 & $2.1 \%$ \\
\hline Explainer & 25 & $5.8 \%$ & 17 & $8.5 \%$ & 3 & $3.1 \%$ \\
\hline Elaborator & 55 & $12.7 \%$ & 23 & $11.4 \%$ & 5 & $5.2 \%$ \\
\hline
\end{tabular}

In phase two, a series of cross tabulations were run to determine if any correlation exists between gender and student responses, moves, and roles.

Figure 1 illustrates the overall percentage of male versus female postings under the 'Initiate and Response' category. The results indicate that male students posted more statements described as Respond (18.1\%), Response-Complement (16.5\%), Stand Alone (3.2\%), and Ill-Formed Turn (.3\%) compared to female students with $17.8 \%, 14.4 \%, 1.4 \%$ and $0 \%$, respectively. However, female students posted more statements described as Initiate (62.1\%) and Reinitiate $(4.2 \%)$ compared to male students with $59.0 \%$ and $2.9 \%$, respectively. 


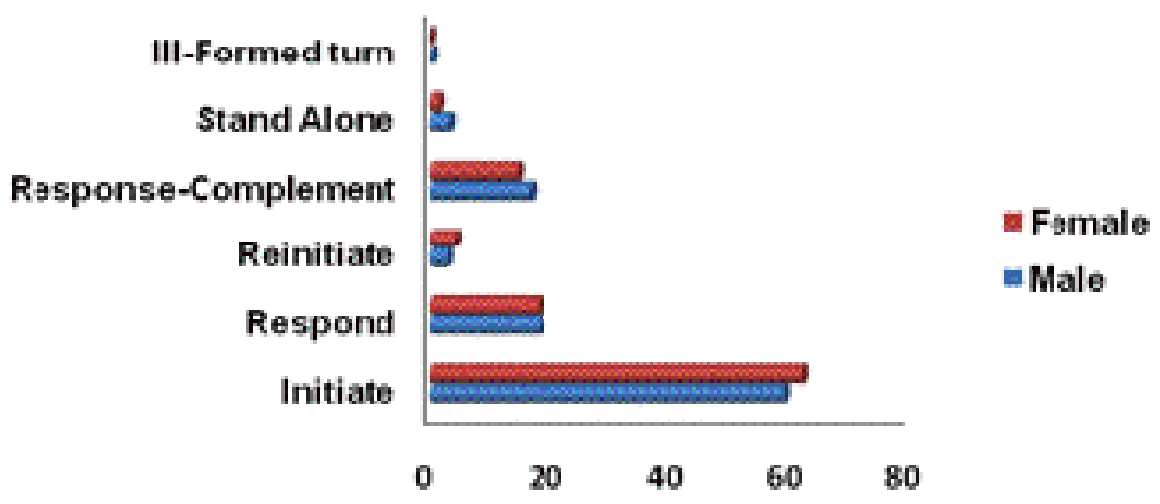

Figure 1. Initiate and Response by Gender Cross Tabulation

Female students dominated with 'moves' in which they Challenged (1.7\%), Justified (1.7\%), Clarified (.8\%), Informed (70.9\%) and Reasoned (7.6\%) at a rate higher than the male students with $1.1 \%, 1.6 \%, 8 \%, 64.9 \%$, and $7.4 \%$, respectively. On the other hand, male students preferred moves that provided more Feedback (17.0\%) and Inquiry (7.4\%) compared to female students with $14.4 \%$ and $2.8 \%$, respectively (see Figure 2).

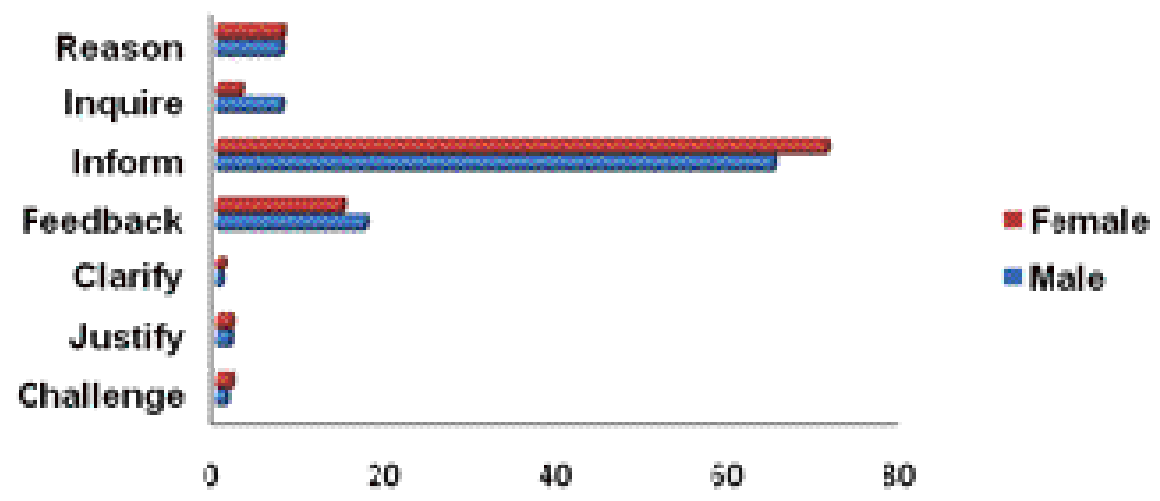

\section{Figure 2. Moves by Gender Cross Tabulation}

When comparing role preferences, male students on average exhibited a higher preference for roles as Inquirer (7.4\%), Evaluator (17.0\%) and Narrator (3.2\%) compared to female students with $2.5 \%, 14.4 \%$, and $1.7 \%$, respectively; while female students on average showed a strong preference for roles as Explainer (7.6\%), Elaborator (69.4\%), Critic (3.4\%), and Clarifier (.8\%) compared to male students with $7.2 \%, 61.9 \%, 2.7 \%$, and .5\%, respectively (see Figure 3 ). 
Wishart \& Guy

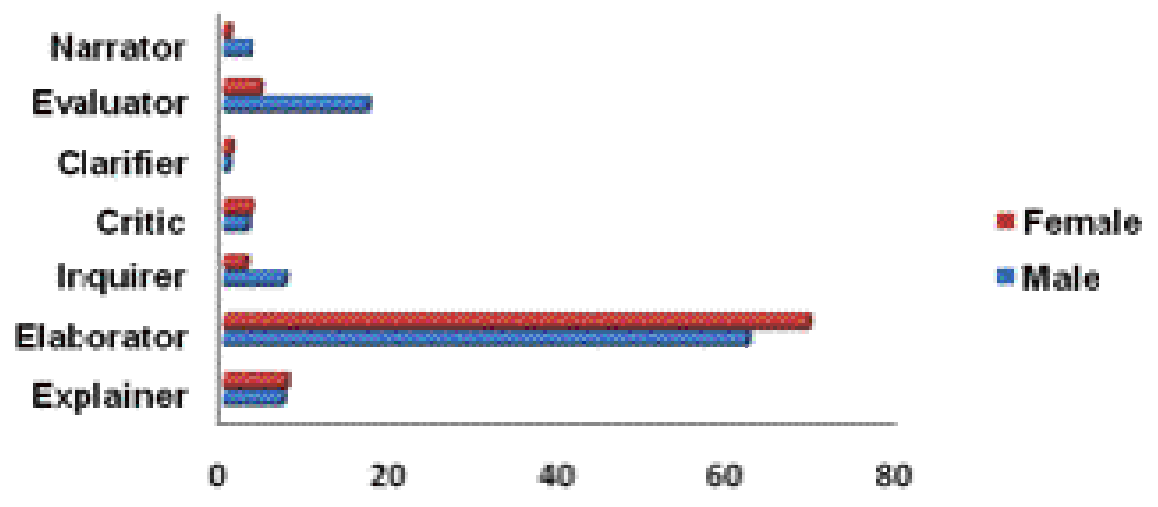

Figure 3. Roles by Gender

Cross Tabulation

\section{Discussion}

Two primary factors influenced the results of this analysis. First, as Gilbert and Dabbagh's (2005) research suggests, explicitly quantifying the number and quality of student postings to the discussion board required during the semester increases participation. Because the instructor's requirements for the discussion board were vague, participation in a majority of the threaded discussions was minimal and inconsistent. With only $30.3 \%-39.5 \%$ of total postings considered responsive statements to an exchange, few 'moves' were taken in response to a single posting. Consequently, many of the postings were initiated simply to inform others of their work, which resulted in no exchange.

Secondly, as an extension of Lisa Lobry de Bruyn's (2004) study, the dialogue often resulted from the instructor's social presence, in the responses to a posting, or instructions to respond to a topical question. The vitality of these discussions largely reflected the instructor's engagement in the students' exchange, as evidenced by the disparity of participation across the courses. Despite the same student enrollment in the first two courses, there were more than twice the number of postings in the first year when the instructor was more active, compared to the second year: 433 and 201 postings, respectively (see Table 8).

Consequently, two specific factors of faculty engagement are believed to have influenced student participation: establishment of a learning community and student demographics. In the first summer, the course opened with a discussion board request for all students to introduce themselves. The instructor responded to each student with either a probing question or statement of confirmation (reinitiating or response-complement statements). In many cases, participants modeled this behavior, engaging each other with questions about their lives or simply welcoming them to the course. This engagement established a learning community that largely set the tone for the rest of the course; the participants were valued and heard by the instructor and students alike. In the second and third courses, the instructor overlooked the introduction and engaged in fewer and less "conversational" postings. Without these modeling behaviors that created the context for relationship building, the students did not appear compelled to engage in discussions, as indicated by the decline in the total percentage of responsive statements over the three years (39.5\%, 38.8\%, and 30.3\%, respectively). As Brannon and Essex (2001) portend, these results suggest that the lack of immediate feedback, daily dialogue, and thoughtful discussion created feelings of social disconnection: "the pitfalls of asynchronous communication." In short, because 
the instructor failed to both create the vital learning community and communicate explicit requirements for responding to exchanges, student dialogue suffered.

Secondly, the instructors' response to the differences in enrollment demographics influenced student participation. While the courses were consistent in a near 50/50 ratio of men and women, less than half the number of students enrolled in the third year (9), as compared to the first two courses (22 and 21 respectively). Importantly, six foreign students were enrolled in the first course; only one foreign student was enrolled in the second, and none in the third. In the first year, the instructor informally appealed to these foreign students to openly share their experiences and perspectives, which lead to more informal discussions and frequent postings as noted above. For fear of alienating and isolating the one foreign student in the second year's class, the instructor did not informally enlist this student's unique experiences for collective learning. The high percentage of basic "response" statements $(21.4 \%)$ may reflect this comparative lack of informal dialogue, since these postings did not anticipate a reply and terminated an exchange. In the third year's small class, all nine students were locals, without any international exposure. The high percentage of "response complement" statements (18.8\%) in this course reveals a general lack of intention to engage in deeper exploration or knowledge creation, since these statements were primarily simple acknowledgements of a contribution.

Because of the limited collective experience in and knowledge of the international arena, combined with the instructors' limited social presence, the discussion board postings in the later two years were comparatively more formal, structured, and limited. Rather than a vital dialogue about the students' thinking, reflection, and learning, by the third course the discussion board contributions became repositories of students' assignments submissions.

The analysis of gender patterns in the discussions over the three years suggests that women appear to be slightly more likely to initiate a discussion in the e-learning environment than men. This finding is compelling given the prevailing literature about gender inequities in the online environments, in which males are believed to generally dominate discussions (Barrett \& Lally, 1999; Sierpe, 2001; Yates, 2001). In this case, our study confirms that in the e-learning environment women are more active than their male counterparts in posting and reading messages (Anderson \& Haddad, 2005; Bellman, et al., 1993; Bostock \& Lizhi, 2005; Gunn, et al., 2003; Wolfe, 2000).

With regard to communication patterns, the women were also more likely to be critical and challenging, as well as feel the need to explain, elaborate, inform, and justify themselves in response to men's predominantly evaluative and inquiring statements. While these differences were minimal, the results suggest that the typical gender differences in communication are nullified in the e-learning environment. Specifically, unlike Carr et al.'s (2004) study, the males did not engage in ritualized adversarial exchanges, and the women exhibited a willingness to challenge and clarify, which were moves that Kneser et al. (2001) found to be predominantly male patterns of communication. These findings suggest that the e-learning environment creates contexts for equitable communication across genders, which is a compelling argument for its unique value in coeducation.

The results of this analysis may also challenge the findings of Allen and Seaman's (2006) survey of 2,200 institutions, in which two-thirds declared, "Students need more discipline to succeed in online course." On the contrary, rather than increasing control over the processes and assessment of online learning, the challenge is for instructors to be present and create dynamic, engaging, and innovative learning opportunities in which they inspire students to participate (Richardson \& Swan, 2003).

The results also confirm Brannon and Essex (2001) recommendations for clear communication protocols and requirements for posting and suggest that the continued development of innovative 
evaluation rubrics is necessary to improve the quality of contributions to an online discussion. As noted earlier by Anderson and Krathwhoh (2001) (see Table 2), a rubric that explicitly describes levels of responses will stimulate learning by challenging students to reflect and think critically, rather than post basic statements of understanding and mere opinion. Additionally, because of both the time and effort required to provide meaningful contributions to the discussions and the value of this learning opportunity for online courses, the relative weight of participation for the final grade should reflect its priority and significance (e.g., at least 10\%).

In response to the formative results of this study, the instructor redesigned future online courses to include personal introductions that will create the learning community, a rubric for assessing individuals contributions that will establish the quality of postings (Table 11), and increased requirements for participation to ensure the quantity and effectiveness of online discussions.

\section{Table 11: Discussion Board Evaluation Rubric}

\begin{tabular}{|l|l|}
\hline \multicolumn{1}{|c|}{ Value of Individual Posting } & \multicolumn{1}{c|}{ Description of Individual Posting } \\
\hline 0 points & No entry, or simple agreement with an exchange \\
\hline $1 \mathrm{pt} \quad \begin{array}{l}\text { Descriptive } \\
\text { Entry }\end{array}$ & $\begin{array}{l}\text { Basic entry that describes one's position without evidence of } \\
\text { engaging with other participants' postings }\end{array}$ \\
\hline $2 \mathrm{pts} \quad \begin{array}{l}\text { Interpretive } \\
\text { Comment }\end{array}$ & $\begin{array}{l}\text { Analytical entry that relates to and builds upon one or more } \\
\text { ideas presented in the thread, demonstrating applied comprehen- } \\
\text { sion of the question or issue that may include ideas beyond the } \\
\text { readings. }\end{array}$ \\
\hline $3 \mathrm{pts}$ Generative \\
Response & $\begin{array}{l}\text { Creative entry that integrates or evaluates multiple views in the } \\
\text { thread and extends beyond the readings, contributing language, } \\
\text { metaphors or analogies that deepen the discussion for all. }\end{array}$ \\
\hline
\end{tabular}

With these innovations in design and assessment of the instructors' courses, it is hoped that the results of a future study will positively confirm the processes and protocols that serve to create lively discussion, collective learning, and knowledge creation in the online classroom.

\section{Conclusion}

In summary, the subject of asynchronous computer-mediated communication has generated much controversy regarding the facilitation of meaningful discourse in online discussion forums. Specifically, the debate is ongoing regarding the use of grading rubrics to ensure and assess full participation in online discussions. This study confirms researchers' findings that support the use of grading rubrics to communicate requirements and assess the quality and quantity of online postings (Anderson \& Krathwhoh, 2001; Brannon \& Essex, 2001; de Bruyn, 2004; Gilbert \& Dabbagh, 2005; Hewitt, 2003).

Kneser et al.'s (2001) Exchange Structure Analysis (ESA) was employed to analyze responses, moves, and roles of students, analyzing the gender differences in online discussions. The results of this study challenge their findings, indicating that typical patterns of gender communication are nullified in the online environment. This study compared the level of participation by male and female students in terms of turns taken, moves made, and role preferences. The results indicate that while male students were more likely to initiate and respond in 4 of the 6 categories (Respond, Response-Complement, Stand Alone, and Ill-Formed Turn), the female students dominated in 'moves' that challenged, justified, clarified, informed, and reasoned, which is contrary prior studies (Carr et al., 2004; Kneser et al., 2001). When comparing role preferences in communication, our study revealed contrary findings. Specifically, male students exhibited a higher pref- 
erence for roles as inquirer, evaluator, and narrator, while female students exhibited a preference for roles as challenger, critic, explainer, elaborator, clarifier, justifier, and reasoned informer.

The current findings confirm recent studies that declare, with effective e-learning technologies, we can create active, engaged, collaborative, and inquiry-based learning opportunities, which can yield unprecedented learning outcomes (Anderson \& Krathwhoh, 2001; de Bruyn, 2004; Gilbert \& Dabbagh, 2005; Hewitt, 2003). Additionally, the study contributes to the scholarship on gender and online learning.

\section{References}

Allen, I., \& Seaman, J. (2006). Making the grade: Online education in the United States. Babson Survey Research Group. Needham, MA: The Sloan Consortium Publishers.

Anderson, D., \& Haddad, C. (2005). Gender, voice, and learning in online course environments. Journal of Asynchronous Learning Networks, 9(1). Available online at http://www.sloanc.org/publications/jaln/v9n1/v9n1 anderson.asp\#anderson7

Anderson, L., \& Krathwohl, D. (Eds.). (2001). A taxonomy for learning, teaching, and assessing: A revision of Bloom's taxonomy of educational objectives. New York: Longman Publishers.

Barrett, E., \& Lally, V. (1999). Gender differences in an on-line learning environment. Journal of Computer Assisted Learning, 15(1), 48-60.

Bellman, T., Tindimubona, A., \& Arias, A. (1993). Technology transfer in global networking: Capacity building in Africa and Latin American. In L. Harasim (Ed.), Global networks: Computers and international communication. Massachusetts: MIT Press.

Bostock, S., \& Lizhi, W. (2005). Gender in student online discourse. Innovations in Education and Teaching International, 42(1), 73-85.

Brannon, R., \& Essex, C. (2001). Synchronous and asynchronous communication tools in distance education. TechTrends, 45(1), 36-42.

Canada, K., \& Pringle, R. (1995). The role of gender in college classroom interactions: A social context approach. Sociology of Education, 68, 161-186.

Carr, T., Cox, G., Eden, A., \& Hanslo, M. (2004). From peripheral to full participation in a blended trade bargaining simulation. British Journal of Educational Technology, 35(2), 197-211.

Celentin, P. (2007). Online education: Analysis of interaction and knowledge building patterns among foreign language teachers. Journal of Distance Education, 21(3), 39-58.

Chang, C. (2008). A case study on the relationships between participation in online discussion and achievement of project work. Journal of Educational Multimedia and Hypermedia, 17(4), 477-509.

Christopher, M., Thomas, J., \& Tallent-Runnels, M. (2004). Raising the bar: Encouraging high level thinking in online discussion forums. Roeper Review, 4(3), 166-171.

Crombie, G., Pyke, S., Silverthorn, N., Jones, A., \& Piccinin, S. (2003). Students' perception of their classroom participation and instructor as a function of gender and context. Journal of Research and Development in Education, 23, 189-197.

Davidson-Shivers, G., Morrison, S., \& Sriwongkol, T. (2003). Gender differences: Are they diminished in online discussions? International Journal on e-Learning, 2(1), 29-36.

Davis, B. (1993). Tools for teaching. San Francisco: Jossey-Bass.

de Bruyn, L. (2004). Monitoring online communication: Can the development of convergence and social presence indicate an interactive learning environment? Distance Education, 25(1), 67-81.

Duffy, T., \& Cunningham, D. (1996). Constructivism: Implications for the design and delivery of instruction. In D. H. Jonassen (Ed.), Handbook of research for educational communications and technology. 
A Project of the Association for Educational Communications and Technology ( pp. 170-198). New York: Simon \& Schuster Macmillian.

Gilbert, P. \& Dabbagh, N. (2005). How to structure online discussions for meaningful discourse: A case study. British Journal of Educational Technology, 36(1), 5-18.

Gunn, C., McSporran, M., Macleod, H., \& French, S. (2003). Dominant or different? Gender issues in computer supported learning. Journal of Asynchronous Learning Networks, 7(1), 14-30.

Hall, R., \& Sandler, B. (1984). Out of the classroom: A chilly campus climate for women? Washington, DC: Association of American Colleges (Report of the Project on the Status and Education of Women).

Hewitt, J. (2003). How habitual online practices affect the development of asynchronous discussion threads. Journal of Educational Computing Research, 28(1), 31-45.

Hewitt, J. (2005). Toward an understanding of how threads die in asynchronous computer conferences. The Journal of the Learning Sciences, 14(4), 567-589.

Ho, S. (2002). Evaluating students' participation in online discussions. Proceedings of AUSWEB02 the Eighth Australian World Wide Web Conference, Twin Waters Resort, Sunshine Coast Queensland, July 6-10, 2002.

Jeong, A. (2005). A guide to analyzing message-response sequences and group interaction patterns in computer-mediated communication. Distance Education, 26(3), 367-383.

Jeong, A., \& Frazier, S. (2008). How day of posting affects level of critical discourse in asynchronous discussions and computer-supported collaborative argumentation. British Journal of Educational Technology, 39(5), 875-887.

Jonnassen, D., Davidson, M., Collins, A., Campbell, J., \& Bannan-Haag, B. (1995). Constructivism and computer-mediated communication in distance education. The American Journal of Distance Education, 9(2), 7-26.

Kneser, C., Pilkington, R., \& Treasure-Jones, T. (2001). The tutor's role: An investigation of the power of exchange structure analysis to identify different roles in CMC seminars. International Journal of Artificial Intelligence in Education, 12, 63-84.

Lacoss, J., \& Chylack, J. (1998). What makes a discussion section productive? Teaching Concerns, Fall.

Levenburg, N., \& Major, H. (2000). Motivating the online learner: The effect of frequency of online postings and time spent online on achievement of leaning \& goals and objectives. Retrieved from: http://as1.ipfw.edu/2000tohe/papers/Levenburg/levenburg.htm

Masters, K., \& Oberprieler, G. (2004). Encouraging equitable online participation through curriculum articulation. Computers and Education, 42, 319-332.

McKenzie, W., \& Murphy, D. (2000). "I hope this goes somewhere": Evaluation of an online discussion group. Australian Journal of Educational Technology, 16(3), 239-257.

McLean, S., \& Morrison, D. (2000). Sociodemographic characteristics of learners and participation in computer conferencing. Journal of Distance Education, 15(2), 17-36.

Palmer, S., Holt, D., \& Bray, S. (2008). Does the discussion help? The impact of a formally assessed online discussion on final student results. British Journal of Educational Technology, 39(5), 847-858.

Pilkington, R. (1999). Analyzing educational dialogue interaction: Towards models that support learning. International Journal of Artificial Intelligence in Education, 12, 1-7.

Poole, D. M. (2000). Student participation in a discussion-oriented on-line course: A case study. Journal on Research on Computing in Education, 33(2), 162-177.

Richardson, J., \& Swan, K. (2003). Examining social presence in online courses in relation to students' perceived learning and satisfaction. Journal of Asynchronous Learning Networks, 7(1), 68-88. 
Sadker, M., \& Sadker, D. (1994). Failing at fairness: How America's schools cheat girls. New York: Scribners Sons.

Salmon, G. (2005). E-tivities. Great Britain: RoutledgeFalmer.

Sierpe, E. (2001). Gender and participation in computer-mediated LIS education topical discussions: An examination of JESSE, the Library/Information Science Education Forum. Journal of Education for Library and Information Science, 42(4), 339-347.

Sinclair, J. \& Coulthard, M. (1975). Towards an analysis of discourse. In M. Coulthard (Ed.), Advances in spoken discourse analysis (pp. 1-35). London: Routledge.

Wolfe, J. (2000). Gender, ethnicity, and classroom discourse. Written Communication, 17(4), 491-519.

Yates, S. (2001). Gender, language and CMC for education. Learning and Instruction, 11, 21-34.

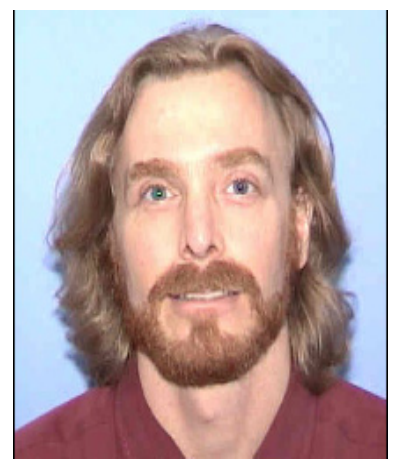

\section{Biographies}

Dr. Craig Wishart has a Ph.D. in Organizational Behavior from Case Western Reserve University. His research and writing has focused upon sustainable community development, education research and reform, as well as change processes in personal and organizational life. Dr. Wishart has fifteen years experience as an organizational consultant in the non-profit and business sectors, including a variety of public, private, educational, community, and international organizations. He has a broad base of experience as a designer and developer of nonprofit business and academic programs, researcher and designer of organizational capacity innovations, designer and facilitator of conferences and team building retreats, and is an author of articles and papers for academics and practitioners.

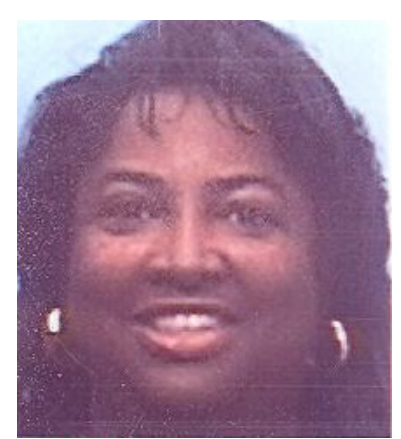

Dr. Retta Guy has an Ed.D. in Curriculum and Instruction with emphasis in Instructional Systems Design from the University of Kentucky. She received her masters in Public Administration from Kentucky State University and a Bachelor of Arts degree in Business Education from the University of Kentucky. Currently, she is an Associate Professor in the Department of Business Information Systems at Tennessee State University in Nashville, Tennessee. Online teaching and mobile learning serves as the basis for her current research for which she has presented at conferences and published in refereed journals and book chapters. She has and continues to conduct workshops and training sessions on the use of web-based course management tools as well as mobile learning technologies. 